\title{
La llegada del palo brasil americano a los mercados europeos: grupos mercantiles transnacionales y pretensiones monopolísticas, 1499-1530*
}

\author{
por \\ Rafael M. Pérez García ${ }^{1}$ \\ Universidad de Sevilla
}

La llegada de los españoles y portugueses a América creó un importante comercio de palo brasil hacia Europa. Durante el primer tercio del siglo XVI el brasil americano fue aceptado en los principales centros textiles europeos desplazando al de origen asiático. Este artículo estudia su distribución por los principales mercados europeos así como las pugnas entre distintos grupos de hombres de negocios por hacerse con el control de la importación del brasil traido desde las Indias de Castilla. Para ello se emplea una abundante documentación procedente del Archivo General de Indias, del Archivo General de Simancas y del Archivo de Protocolos de Sevilla.

Palabras Clave: palo brasil americano; industria textil europea; mercaderes; mercados.

Cómo Citar Este Artículo / Citation: Pérez García, Rafael M., "La llegada del palo brasil americano a los mercados europeos: grupos mercantiles transnacionales y pretensiones monopolísticas, 1499-1530", Revista de Indias, LXXXI/283 (Madrid, 2021): 603-634. https://doi.org/10.3989/revindias.2021.017.

* Este trabajo se ha realizado en el marco del Proyecto Europeo de Investigación "Connected Worlds: The Caribbean, Origin of Modern World (ConnecCaribbean-823846)", financiado por el Programa Horizonte 2020 de la Unión Europea; y del Proyecto de I+D "Mercados y tratas de esclavos en el Atlántico ibérico del siglo XVI (HAR2016-78056-P)”, financiado por el Ministerio de Economía, Industria y Competitividad del Gobierno de España.

${ }^{1}$ rperez4@us.es, ORCID iD: https://orcid.org/0000-0002-3558-5104 


\section{INTRODUCCIÓN}

Desde hace varias décadas, la historiografía ha venido recordando que no fue solo la búsqueda de las especias y de metales preciosos la que impulsó a los europeos del siglo XV a desarrollar su exitosa expansión ultramarina a través del Atlántico. Como se ha demostrado, la explotación de nuevas pesquerías o la obtención de esclavos en África, entre otros productos, no fueron incentivos menores ${ }^{2}$, pues cubrieron notables requerimientos tanto de alimento como de mano de obra existentes en las sociedades europeas. Lo mismo sucedió con la industria textil europea del Cuatrocientos, que atendía la creciente demanda de vestimentas de amplias capas de la población europea (tanto de carácter suntuario para las clases altas como de otras menos costosas destinadas a las clases medias de la sociedad) ${ }^{3}$ cuyas imperiosas necesidades de materias colorantes acompañaron en todo momento a los exploradores y mercaderes que abrían nuevas rutas y mercados: así, entre los productos buscados en aquella expansión atlántica finimedieval destacaron el pastel, clave en el proceso de teñido de los tejidos, además de para conseguir los colores azules; la orchilla, usada para los violetas; o el brasil, para los rojos y escarlata, además de para intensificar u oscurecer los azules ${ }^{4}$.

Por todo ello, la historiografía no ha dejado de prestar atención al desarrollo de la producción y comercialización de la hierba pastel de las islas Azores $^{5}$ o de la orchilla en las Canarias y en la costa atlántica norteafricana. En ambos casos, ya en el siglo XV importantes grupos económicos internacionales de origen italiano y burgalés se interesaron en la obtención y comercialización de esas plantas, a fin de suministrarlas a la industria europea. En los últimos años del siglo XV y primeros del XVI, la orchilla de las Canarias y de Berbería, que se comercializaba hacia Cádiz y se redistribuía desde ella hacia los puertos del Mediterráneo occidental y central ${ }^{6}$, ya estaba bajo control de hombres de negocios burgaleses, que pugnaban entre sí por su monopolio ${ }^{7}$. En el caso del pastel, en esa misma cronología eran también fundamentalmen-

${ }^{2}$ Godinho, 1991, vol. IV: 127-137, 151-161. Wallerstein, 2010, vol. 1: 59-64. Santana Pérez y Santana Pérez, 2014: 88-91, 121-131.

3 Mueller, 1992: 184-186. Eberhard, 1992: 248, 251-252.

${ }^{4}$ Córdoba de la Llave, 2017: 78-79. Cardon, 2016: 77, 103.

${ }^{5}$ Fernández Chaves, 2016.

${ }^{6}$ Un contrato de fletamento de 1506 describe con claridad la ruta marítima de distribución de la orchilla desde las islas Canarias hasta Cádiz, y desde ésta hacia Valencia, Marsella, Aigues Mortes, Génova, Civitavecchia, Nápoles y Venecia (Morales Padrón, 1961: 334-335).

7 Sánchez Martín, 1992. Bello León, 2006: 72-74. Aznar Vallejo, 1991, vol. 1: 348-349, 369. Palenzuela, 2003: 106. 
te mercaderes burgaleses quienes lo introducían desde Toulouse y las Azores en Andalucía a través de Cádiz ${ }^{8}$. No debemos menospreciar unos hechos que nos ayudan a explicar el temprano interés de las multinacionales burgalesas en la exploración y explotación del Atlántico medio y de las costas de la llamada Guinea durante la segunda mitad del siglo XV, siempre en concurrencia con los italianos ${ }^{9}$; tampoco es casual que los primeros explotadores oficiales de la orchilla producida en las islas de Cabo Verde, allá por 1469, fueran dos mercaderes castellanos de Sevilla ${ }^{10}$. Esos intereses no desaparecieron cuando se produjo la llegada a América de los europeos en 1492; al contrario, el enorme valor alcanzado por las importaciones de materias tintóreas americanas en el siglo XVI nos avisa de que nos encontramos ante un tema crucial ${ }^{11}$. En este artículo se estudia el inicio de la explotación y comercialización hacia Europa de otro de aquellos productos vegetales de uso tintóreo, el palo brasil americano. Se analizará aquí la primera fase de la historia de este producto que se extiende desde la década de 1490 hasta los últimos años de la de 1530, y que hasta el momento, en contraste con lo que sucede con el pastel o la orchilla, no ha merecido la atención necesaria por parte de la historiografía.

\section{LA TRANSICIÓN DEL BRASIL ASIÁTICO AL AMERICANO EN LA ECONOMÍA EUROPEA, 1499-1520}

Diversas variedades del palo brasil procedentes de diferentes regiones de Asia eran conocidas en la Europa medieval al menos desde el siglo XII. Algunos viajeros medievales italianos en Oriente se refirieron a ellas frecuentemente usando el término "verzino», que no es sino una variedad de la propia palabra «brasil», la que de hecho emplea Marco Polo cuando habla del producido en la isla de Ceilán ${ }^{12}$. Era uno de los colorantes rojos de los que disponía la industria textil durante aquellos siglos ${ }^{13}$, aunque también se utilizaba para el maquillaje. Los datos conocidos, aunque escasos, muestran la llegada del brasil asiático a los principales centros mercantiles europeos medievales a través de las rutas de Oriente. A finales del siglo XII se comercializaba

\footnotetext{
8 Palenzuela, 2003: 104-105. Véase también Brumont, 1994: 29-35.

9 Ramos Pérez, 1992: 132-142. Bello León, 2018.

10 Matos, 2005: 120.

11 Lorenzo Sanz, 1979, tomo I: 545-546.

12 The Travels of Marco Polo, 1993, vol. II: 380-381.

13 Carande, 1989: 351. Gual Camarena, 1976: 239-240.
} 
brasil a Génova desde Siria; desde Génova a su vez se redistribuía a Bujía, en el norte de África ${ }^{14}$. En la misma época, la madera de brasil llegaba a Pisa desde Alejandría ${ }^{15}$. Las aduanas del Rosellón y de Barcelona recogen la entrada de cargas de «brazill» durante la primera mitad del siglo XIII ${ }^{16}$, sin duda procedente también de Oriente. Chaucer lo menciona en sus cuentos, en el siglo XIV, en relación con Inglaterra ${ }^{17}$. En un centro textil castellano como Cuenca, el brasil era un producto tintóreo habitual en 1421, junto con el pastel, la orchilla y otros ${ }^{18}$. De Génova se conocen datos sobre el uso del brasil en 1454 para teñir los paños ${ }^{19}$. En la misma época se podía encontrar en el puerto de Dubrovnick, aquí llamado «varzino» por las fuentes locales ${ }^{20}$. En Rouen y París se documenta brasil en 1477-1478 junto con otros muchos productos introducidos allí gracias a las redes del comercio mediterráneo de larga distancia, llegados seguramente por la vía de Alejandría ${ }^{21}$. En Amberes, todavía en 1493 se vendía madera de brasil asiático, pues en esa fecha debía proceder necesariamente de Oriente ${ }^{22}$. En Valencia, los documentos conocidos de 1488 y 1494 muestran a las galeras venecianas descargando palo brasil procedente de Levante $^{23}$. El carácter de producto precioso y valorado que tenía el brasil en la economía europea medieval queda de manifiesto en la regulación hecha por el rey Alfonso V de Portugal del trato de Guinea en 1470, que prohibía taxativamente el rescate de «pedras preciossas nem tintas de brasill ou alacar [laca]», dejando sin efecto los privilegios o licencias previas que lo hubiesen permitido a particulares ${ }^{24}$.

El descubrimiento de América y el hallazgo de otras variedades de brasil alteraron radicalmente la disponibilidad del producto en Europa. Las tempranas menciones al mismo delatan el interés que suscitaba. La primera aparece en el segundo viaje de Colón por el mar Caribe ${ }^{25}$, que se refiere a «la grande cantidad de brasil» que allí había ${ }^{26}$. También Américo Vespuccio en la carta

14 Krueger, 1933: 395.

15 Lopez, 1969: 40.

16 Arroyo Ilera, 1961: 146.

17 The Travels of Marco Polo, 1993, vol. II: 380.

18 Iradiel, 1974: 176.

19 Heers, 1961: 250.

20 Belamaric, 2014: 286.

${ }^{21}$ Mollat, 1952: 230, 327.

${ }^{22}$ Doehaerd, 1962, vol. II: 122.

23 Guiral-Hadziiossif, 1989: 408.

${ }^{24}$ Monumenta, 1958, vol. I: 444-445. Extracto del documento en Alguns documentos..., 1892: 33

${ }^{25}$ Guidi Bruscoli, 2014: 107.

${ }^{26}$ Colón, 1986: 227. 
que escribe desde Sevilla en julio de 1500 dirigida a Lorenzo de Médici en Florencia, da cuenta de que en su viaje por la costa norte de Sudamérica encontraron abundante palo brasil. En una de las islas por las que pasaron, «que tenía sus casas construidas en el mar como Venecia, con mucho arte, [...] encontramos que tenían colmadas las casas con finísimo algodón, y las vigas de sus casas eran también de brasil, y les quitamos mucho algodón y brasil, volviendo luego a nuestros navíos». Parece claro que Vespuccio consideraba que el algodón y el brasil eran productos atractivos para el importante centro textil que era la Florencia de los Médici, puesto que continúa: «Habéis de saber que en todas partes donde saltamos a tierra, encontramos siempre gran cantidad de algodón, y los campos llenos de plantas de él, tanto que en esos lugares se podrían cargar cuantas carabelas y navíos hay en el mundo, con algodón y brasilı ${ }^{27}$.

Por sus conocidas propiedades tintóreas y su valor económico, la madera de brasil americano se convirtió enseguida en un producto codiciado. Aunque no tienen por qué ser acertadas, resultan clarificadoras las conocidas palabras que le dedica el cronista João de Barros en sus Décadas da Asia acerca del cambio de nombre de las tierras inicialmente llamadas de Santa Cruz por los portugueses: «daquella térra começou de vir o páo vermelho chamado brasill» hasta el punto de «que este nome ficasse na boca do povo, e que se perdesse o de Sancta Cruz, como que importava mais o nome de hum páo que tinge

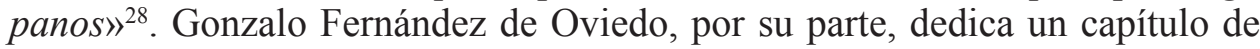
su Historia a «los árboles del brasil» que había en la isla de Santo Domingo y en la Tierra Firme:

Brasil es árbol muy conosçido e útil e provechoso a los tintóreos de paños e lanas e a los pintores, e para otras cosas, e hay mucho en algunas partes de la Tierra Firme, para cargar quantas naves quissieren dello. Y assimismo lo hay en algunas islas de la costa de la Tierra Firme, e haylo en esta nuestra isla Española, no lexos, sino a par del lago de Xaragua e por aquellas sierras. Es árbol no muy alto ni derecho, su color es morada, después ques fecho rajas que tira al morado o color de púrpura; e en la provinçia e montañas de Sanct Miguel, que otros llaman del Tiburón, hay muchos árboles destos [...]. Pero donde mayor cantidad hay desta leña e árboles de brasil es en la gran costa de la Tierra Firme, a la banda de nuestro polo ártico, de grandíssimos boscajes desde el grande río Marañón la costa arriba haçia el Oriente ${ }^{29}$.

\footnotetext{
27 Vespucio, 1985: 23.

${ }^{28}$ Citado en Monumenta, 1958, vol. I: 445.

${ }^{29}$ Fernández de Oviedo, 1851, tomo I: 348.
} 
Y apostilla: «E porques árbol tan conosçido e notable, no diré más dél, pues hay muchos que tienen experiençia de sus utilidades e provechos y efetos de sus colores e propriedades, que podrán mejor testificar sus operaçiones $»^{30}$.

\section{LOS COMIENZOS DE LA IMPORTACIÓN DEL PALO BRASIL AMERICANO Y LA COMPETENCIA POR LOS MERCADOS EUROPEOS}

Las llegadas de cargamentos de palo brasil a la Península Ibérica desde el Caribe comenzaron muy pronto. La primera noticia de una venta de brasil americano en Andalucía es de 1499, a precio de 5,75 ducados el quintal ${ }^{31}$. En Portugal, ya en 1502 el rey don Manuel arrendó a Fernão de Noronha y a otros cristãos novos el comercio de ese producto y de la exploración de la costa brasileña para el periodo 1502-1505, un hecho del que uno de los líderes de la comunidad florentina en Sevilla, Piero Rondinelli, se hizo eco, revelando el interés que despertaba el asunto entre los mercaderes italianos. Tras la finalización de ese contrato, Noronha obtuvo otro por una década más, con la obligación de importar cantidades notables del producto (entre $10.000 \mathrm{y}$ 20.000 cantari vacilan las fuentes), cerrar la entrada al procedente de la India y convertir Lisboa en un gran centro de redistribución internacional del brasil americano hacia Flandes, Castilla e Italia. Aunque de peor calidad que el asiático, su menor precio consiguió barrer a este último del mercado, si bien todavía en 1518 llegaban a Lisboa pequeñas cantidades desde la India ${ }^{32}$.

En España, los Reyes Católicos tampoco tardaron en regular su importación y distribución, además de utilizarlo para hacer mercedes y pagar servicios a distintas personas, si bien hay que tener en cuenta que en virtud de las capitulaciones de Santa Fe, Cristóbal Colón disfrutaba de la décima parte del brasil obtenido en América. En abril de 1500 la corona firmó un asiento con el mercader genovés Francisco de Riberol y el judeoconverso aragonés Francisco Sánchez de la Tesorería, ambos socios y vecinos de Sevilla ${ }^{33}$, por el que éstos se comprometían a proporcionar en algún puerto de las Indias durante siete años 7.000 quintales de brasil de las tierras recién descubiertas, a razón de 1.000 quintales anuales y precio de 3,5 ducados por quintal. Riberol y Sánchez obtenían un monopolio sobre el brasil además de la licencia por tres años para descubrir nuevas islas en la demarcación correspondiente a los

\footnotetext{
${ }^{30}$ Idem.

31 Ladero, 2008: 155.

32 Guidi Bruscoli, 2014: 107-109. Véase también Azevedo, 1988: 237-238.

33 Perez, 2016: 200-201. Sobre las actividades económicas de ambos, Otte, 1996: passim.
} 
Reyes Católicos ${ }^{34}$, una concesión codiciada dado que Riberol era uno de los grandes mercaderes genoveses involucrados en el tráfico de los productos atlánticos (como la orchilla o el azúcar de las Canarias), y Juan Sánchez de la Tesorería sería en los años siguientes un gran inversor en las expediciones al Caribe ${ }^{35}$ cuyos negocios se articulaban con las grandes plazas financieras de Medina del Campo y Valencia ${ }^{36}$. Al igual que en el caso portugués, en este asiento se expresaba la idea de competir con el brasil «que se trae por vía de Levante». Colón, por su parte, recibió en 1501 confirmación de su derecho a recibir el diezmo del brasil producido por los mercaderes del asiento, fijándose en 111 quintales los que debería recibir sobre el total de 1.000 anuales y que el almirante podría traer a España desde Santo Domingo ${ }^{37}$. No obstante, ya en febrero de 1502 el asiento había sido anulado por parte de la corona ${ }^{38}$.

Cádiz, que seguía siendo la cabecera del comercio africano ${ }^{39} \mathrm{y}$ en aquellos años se pretendía erigir también en el único puerto habilitado para las Indias ${ }^{40}$, se convirtió enseguida en el centro castellano de redistribución del brasil, como ya lo era de la orchilla de Canarias y Berbería ${ }^{41}$. El asiento de 1500 menciona el brasil «que ahora está en Cádiz», entiéndase almacenado. En una cédula real de 1501 por la que los monarcas contestaban al funcionario Jimeno de Briviesca, leemos que «çerca de lo que escrevys del brasyl, paréçenos que es bien que se traya como desís en los navíos que agora van a la ysla Española e se almasenen en la çibdad de Calis para que de allí se saque e se

34 Asiento sobre el brasil y confirmación, Sevilla, 20 de junio de 1500, Archivo General de Simancas, Simancas, Valladolid (AGS), Registro General del Sello, VI-1500, fol. 1.

35 Mira Caballos, 2014: 208-211. Ejemplo de una de estas empresas para llevar simientes, provisiones y mercaderías a la isla Española en Archivo General de Indias, Sevilla (AGI), Indiferente (I), 418, 1.1, f. 82r-v. Toledo, 12 de septiembre de 1502.

${ }^{36}$ Otte, 1996: 174.

${ }^{37}$ Copia de esta cédula de 27 de septiembre de 1501 ha sido publicada en Muro Orejón, Pérez-Embid y Morales Padrón, 1967: 177. En los años siguientes Colón no dejó de reclamar y obtener el cobro del diezmo sobre el brasil venido de las Indias. En 1504, a petición de Alonso Sánchez Carvajal, que actuaba en nombre del almirante, la corona accedió a entregarle el diezmo del brasil que había venido de las Indias en «los navíos que llevó don frey Nicolás de Ovando nuestro governador dellas» (Medina del Campo, 29 de febrero de 1504, AGI, I, 418, 1. 1, f. 129v).

${ }^{38}$ Una cédula de 18-II-1502 reza que «el qual dicho asiento a consentimiento dellos [Riberol y Sánchez de la Tesorería] se dio por ninguno» (Andrés Díaz, 2008: 422-423).

39 Rumeu, 1976: 37-41. González Arce, 2017: 71-74.

${ }^{40}$ La provisión real de 2-VI-1497 establecía «que todos los navíos que ovieren de yr a la parte de las dichas yslas [...] ayan de partyr desde la çibdad de Caliz y no de otra parte alguna» (Muro Orejón, Pérez-Embid y Morales Padrón, 1967: 94).

41 Sánchez Martín, 1992. Morales Padrón, 1961: 334-335. Salvador Esteban, 1988: 633, 626. Aznar, 1991, vol. 1: 348-349. 
venda quando fuere tienpo» ${ }^{42}$. Sea como fuere, desde Cádiz, los mercaderes genoveses de la ciudad parecen haberse hecho con el trato del palo brasil. Además de varias cédulas reales de 1501 que se refieren al «asiento» concertado con varios mercaderes «cerca del dicho brasil»»" ${ }^{43}$, algunos documentos notariales sevillanos de los años siguientes muestran a otros mercaderes genoveses involucrados en el trato del brasil, así Francisco Cataño, estante en Cádiz en $1504^{44}$, y a Gaspar Espíndola, estante asimismo en Cádiz, cobrando en esta ciudad 60 quintales de brasil a Leonardo y Visconte Cataño, mercaderes genoveses vecinos de Cádiz ${ }^{45}$. Estos dos últimos parecen haberse implicado especialmente en el comercio del brasil, al menos así lo indican varios apuntes del cargo de la contabilidad de la Casa de la Contratación de Sevilla del año 1505 que se refieren a ellos como mercaderes genoveses estantes en Cádiz, que alquilaban a la Casa unos almacenes en esa ciudad donde se depositaba el brasil que llegaba de América, además de encargarse de su procesado: así, la Casa les entregó 1.000 maravedís para que pagasen a «los moros e otras personas que entendieron en pesar el dicho brasil al tiempo que se reçibió cargo para Flandes», y otros 3.000 maravedís se dieron «a los Cataños por de su fatoría de manifiçiar el brasyl susodicho que fueron ochoçientos quintales ${ }^{46}$. Desde Cádiz, Leonardo y Visconte Cataño enviaban brasil a los mercados de Flandes y conectaban el movimiento de dinero y de productos entre Sevilla y el Caribe ${ }^{47}$. Habida cuenta de la asentada ruta comercial que unía Cádiz y Génova desde la Edad Media y por la que fluía abundantemente el oro africano hacia la república ${ }^{48}$, parece plausible pensar que por ella se trató de canalizar el nuevo brasil caribeño para introducirlo en el tradicional mercado italiano. De hecho, en 1508 se entregaron a Franco Cataño, genovés estante en Flandes, 10 quintales y 2 libras de brasil limpio «para que los lle-

${ }^{42}$ AGI, I, 418, 1. 1, f. 67r-bis.

43 AGS, Cámara de Castilla (CC), libro de cédulas 5, f. 186v-187r, 220r, 220v.

${ }^{44}$ Catálogo de los fondos americanos..., 1990, vol. VII, doc. 169, Sevilla, 7-VI-1504.

${ }_{45}$ Catálogo de los fondos americanos..., 1990, vol. VII, doc. 171, Sevilla, 10-VI-1504.

46 Ladero, 2008: 278.

${ }^{47}$ En 1509, Alejandro Cataño, mercader genovés estante en Sevilla, les daba poder para cobrar una serie de deudas de dinero y mercaderías en las Indias, que además les traspasaba (Catálogo de los fondos americanos..., 2000, vol. VIII, doc. 646, Sevilla, 21-XI-1509). Un año antes era Leonardo Cataño quien desde Sevilla apoderaba a Jerónimo de Grimaldo y Antonio Italián, mercaderes genoveses estantes en Indias, para que recibiesen allá las mercancías que enviaba y cobrasen sus deudas (Catálogo de los fondos americanos..., 2000, vol. VIII, doc. 468, Sevilla, 23-III-1508).

48 Rumeu, 1976: 31-35. 
vase a Génova e los fiziese ensayar para que allí se toviese notiçia del dicho brasil», aunque no parece haber conseguido un efecto inmediato ${ }^{49}$.

La Casa de la Contratación llevó a cabo un control bastante estricto sobre el trato del brasil desde aquellos primeros años. Como explica Ladero Quesada, se trataba de «un producto cuya importación y venta se reservaba la corona $\gg^{50}$. Ésta, además, concedió mercedes de brasil a diversos particulares sobre el que correspondía al diezmo de Colón, lo que insiste en la idea del monopolio de venta que pretendía ejercer la Casa de la Contratación. En aquellos casos en que el almirante no se lo vendió, la misma corona cargó esas mercedes sobre el producto en manos de los mercaderes firmantes del asiento del brasil y, finalmente, en caso de que tampoco éstos se lo proporcionasen, los beneficiarios de aquellas mercedes podrían obtenerlo y cortarlo directamente en La Española u otras partes de las Indias para traerlo a España. Entre 1500 y 1501, fue el caso de Diego de Peñalosa (con una merced de 10 quintales de brasil) ${ }^{51}$, don Juan de Guevara y otras personas (20 quintales) $)^{52}$, Gonzalo de Valdenebro y otros más (10 quintales) $)^{53}$, Pedro Fernández Coronel (20 quintales), Pedro de Terreros (10 quintales), Cristóbal de Torres (10 quintales), Diego Tristán (10 quintales) y Pedro de Salcedo (10 quintales) ${ }^{54}$, etc. En todos estos casos, la Casa fue la encargada de hacer efectivo un sistema de ventas casi compulsivas que afectaban al brasil tanto de Colón como de los mercaderes del asiento. En enero de 1502, los reyes prometieron a Andrés Velázquez, «contador de nuestra casa» que iba a las Indias, entregarle a su regreso 50 quintales «del brasil que de allá viniere» ${ }^{55}$. En 1503, la reina Isabel ordenó a sus funcionarios de Sevilla responsables del tráfico indiano (el doctor Matienzo, Francisco Pinelo y Jimeno de Briviesca ${ }^{56}$ ) que entregasen a Cristóbal Guerra, vecino de Sevilla y explorador del Caribe, 41 quintales y 60 libras de brasil «de lo que está en poder del mercader genovés Benito Castellón, el cual dicho Cristobal Guerra a de aver e le pertenesçe del quinto

${ }^{49}$ La data del brasil de 1508 de la Casa de la Contratación añade: «de lo qual no se ha avido ningún retorno» (Ladero, 2008: 319).

${ }^{50}$ Ibidem: 155.

51 Sevilla, 19 de mayo de 1500, AGS, CC, libro de cédulas 4, f. 83.

52 Sevilla, 13 de julio de 1501, AGS, CC, libro de cédulas 5, f. 186v-187r.

53 Sevilla, 25 de agosto de 1501, AGS, CC, libro de cédulas 5, f. 220v.

${ }^{54}$ AGS, CC, libro de cédulas 5, f. 177v-178r (Granada, 12-VII-1501) y f. 220r (Granada, 25-VIII-1501).

55 Sevilla, 2 de enero de 1502, AGI, I, 418, 1. 1, f. 77v.

${ }^{56}$ En 14 de febrero de 1503 habían sido nombrados escribanos de la Casa de la Contratación. AGI, Contratación, 5784, 1. 1, f. 1v-2. 
del brasil que él truxo de las Yndias e tierra que descubrió el postrero viaje que allá hizo por mi mandado» ${ }^{57}$.

Solo el hecho de que las importaciones de brasil fuesen ya notables en una fecha tan temprana como ésta explica que en agosto de 1503 la reina promulgase una pragmática prohibiendo que nadie pudiese «traer nin meter, nin vender nin comprar ellos nengund brasil que se truxere a estos dichos mis reynos e señoríos de nenguna parte que sea, salvo solamente de lo que se truxere de las dichas mis islas e Tierra Firme del dicho mar oceáno» bajo pena de pérdida del brasil. El motivo de esta medida era:

... que a estos mis reynos se trae a vender, ansí por mar como de tierra muncho brasil de otros reynos, lo qual non es tal nin tan bueno cual combiene para que las obras que con ellos se facen sean perfetas e buenas, porque por gracia de Nuestro Señor ay en estos mis reynos muncha abundancia de brasil del que se trae de las mis islas e Tierra Firme del mar océano, lo qual es muy más fino que non lo que se trae de otras partes, con lo qual se podrán mexor labrar todas las cosas que rrequieren labrarse con el dicho brasil [...] e mi yntinción es de mandar proveer para quel precio del dicho brasil non se suba más de como agora vale.

En realidad, se trataba de limitar la competencia y controlar el precio más que de garantizar la calidad, en un momento en que la corona aspiraba a crear en La Española un gran emporio de producción de plantas tintóreas de utilidad industrial. Unos meses antes, en marzo de 1503, Fernando el Católico había remitido al gobernador Nicolás de Ovando una instrucción secreta inquiriéndole sobre la productividad del brasil, además de enviarle semillas de pastel y rubia para que ensayase su cultivo en las nuevas tierras ${ }^{58}$. Sin embargo, la prohibición de 1503 no parece haber tenido los efectos positivos que se perseguían. A pesar de ella, las importaciones de brasil procedentes de regiones ajenas al territorio de la demarcación de Castilla hubieron de continuar en los años siguientes, lo que obligó a Fernando el Católico en 1510 a recordar la vigencia de la pragmática de $1503^{59}$, que fue pregonada por toda Castilla ${ }^{60}$. Obviamente, en aquellos años se trataba no solo de eliminar del mercado español el brasil recibido por la vía tradicional de Oriente en barcos italianos, sino también el palo brasil traído por navegantes y mercaderes portugueses y llegado a Castilla desde Portugal, adonde también fluía en abundancia, como prueban diversas cuentas de mercancías introducidas en Lisboa entre 1505 y

${ }^{57}$ Cédula real, Alcalá de Henares, 23 de mayo de 1503, AGI, I, 418, 1. 1, f. 104r.

58 Río, 1991: 271.

${ }^{59}$ Los textos de las cédulas reales de 29-VIII-1503 y 15-VI-1510 se hallan publicados en Colección de documentos inéditos..., 1879, tomo 32: 66-71.

${ }^{60}$ Ladero, 2008: 156. 
$1509^{61}$. Sabemos de uno de aquellos mercaderes genoveses de Cádiz, Niculoso Moreno, que fue condenado por la Casa de la Contratación por una compra ilegal de brasil, aunque en 1513 ya había sido exonerado de su pena ${ }^{62}$.

La Casa de la Contratación llevó desde sus primeros años de existencia una exhaustiva contabilidad del brasil llegado y vendido. Las cantidades de brasil y sus valores de mercado no son en absoluto despreciables, pues en 1508 la Casa disponía de algo más de 1.866 quintales que fueron valorados en casi 15.000 ducados $^{63}$, si bien se trataba de un precio realmente inflado respecto al que corría en el mercado. No obstante, a pesar de la prohibición de importar brasil de origen portugués u oriental, de los tempranos envíos de producto desde Cádiz ${ }^{64}$ a Flandes ${ }^{65}$ en 1504 y en 1505, donde era vendido por el mercader sevillano García Suárez ${ }^{66}$, y de otras importantes cantidades en 1508 (más de 660 quintales de brasil limpio en cuatro naos distintas) consignadas al mismo para su venta allá, parece que las ventas se estancaron ya en aquellos años. Carande recoge las quejas de los comerciantes que operaban en la corona de Aragón que en esos años $(1503,1507,1510)$ exclaman: «Quisiéramos no haberlo visto nunca», quizás por «su propensión a secarse, lo que exigía renovar a menudo las existencias $»^{67}$. A fin de promocionar el producto y estimular su demanda, aquel mismo año de 1508 se enviaron muestras de brasil a la ciudad de Génova, y al mercader genovés Douayn de Marín, en Córdoba, ciudad que poseía una potente industria textil que demandaba productos tintóreos ${ }^{68}$ y que se abastecía de los mismos a través de Sevilla ${ }^{69}$;

${ }^{61}$ “Cartas de quitação del Rei D. Manuel”, 1903: 167, 279. Véase también Guidi Bruscoli, 2014: 109-110.

${ }^{62}$ Catálogo de los fondos americanos..., 2007, vol. III, doc. 48, Sevilla, 3-IX-1513.

${ }^{63}$ Ladero, 2008: 156.

${ }^{64}$ Ibidem: 245.

${ }^{65}$ Desde Flandes, la madera de brasil era a su vez redistribuida hacia el interior del continente. Diversos documentos de Amberes de 1506, 1507 y 1512, prueban un continuado transporte del mismo hacia Colonia (Doehaerd, 1962, vol. II: 209, 215, 228, 229, 240, 245, 252, 253; vol. III: 14, 43); también a Maastricht en 1512 (Doehaerd, 1962, vol. III: 9, 15) у ese mismo año a Lieja (Doehaerd, 1962, vol. III: 10), Kessel (Doehaerd, 1962, vol. III: 11), Hildesheim (Doehaerd, 1962, vol. III: 34) y Brunswick (Doehaerd, 1962, vol. III: 17); para 1513 se conocen datos de envíos a Lieja (Doehaerd, 1962, vol. III: 84), Frankfurt (Doehaerd, 1962, vol. III: 102) y Metz (Doehaerd, 1962, vol. III: 107). No obstante ignoramos en qué medida se trataba de palo brasil portugués o español, aunque es seguro que ambos llegaban a Amberes.

${ }^{66}$ Ladero, 2008: 156, 278, 290, 297, 326.

${ }^{67}$ Carande, 1989: 351.

${ }^{68}$ Ladero, 2008: 319-320.

${ }^{69}$ Fortea Pérez, 1981: 296, 301 
hasta donde sabemos, el brasil americano acabaría invadiendo la tintorería cordobesa durante la primera mitad del siglo XVI, si bien a comienzos del mismo existían reticencias y se produjeron prohibiciones sobre determinados empleos del brasil en la ciudad ${ }^{70}$.

Los datos de entrada de brasil y venta por la Casa de la Contratación entre 1512 y 1518 reflejan claramente una contracción del mercado, siendo aquella incapaz de impedir que una parte sustancial del mismo (el $9 \%$ entre 1512 y agosto de 1515) se estropease en sus almacenes por falta de compradores $^{71}$. Sin duda, la década de 1510 no fue buena para las ventas del brasil americano procedente de las Indias de Castilla, puesto que entre 1512 y 1518 la Casa solo ingresó 853.700 maravedís por ellas, cuando el valor de las mismas había supuesto unos seis millones y medio hasta $1511^{72}$. A finales de la década las existencias se estaban pudriendo. Una cédula real de mayo de 1519 recordaba a los oficiales de la Contratación:

... ya sabéis quanto tiempo a que tenéis en esa Casa harta cantidad de brasil, e aunque muchas vezes vos he enviado a mandar que los vendáis al mejor precio que se hallase, fasta agora no lo avéis podido vender, e así por esto como porque cada día de quantos se dilactare la venta del dicho brasil vale menos.

Como solución, se les ordenaba buscar a alguien que «tome junto el brasil que agora ay en esa Casa» a razón de 1.050 maravedís el quintal $(2,8$ ducados/quintal $)^{73}$. Esta situación y mandato real estarían en el origen de la cesión de «el almacenaje y comercialización directa del brasil a mercaderes que se hicieron cargo del que había en la Casa y del que seguía llegando: 2.506 quintales en total», 40 de los cuales pasaron en octubre de 1519 al poderoso mercader burgalés Cristóbal de Haro y 2.466 al banquero genovés de Sevilla Gaspar Centurión, que actuaba en nombre de don Diego de Acuña, arcediano de $\mathrm{Moya}^{74}$; en un segundo momento, el arcediano habría vendido el brasil al propio Centurión, al cambiador Juan Díaz de Alfaro y al mercader vizcaíno Domingo de Ochandiano, vecinos de Sevilla, por solo 800 maravedís el quintal (2,133 ducados por quintal), un precio que denota la tendencia a la baja del precio del producto desde principios de siglo ${ }^{75}$. En efecto, según una declaración realizada en 1528 por el propio contador de la Casa de la Con-

\footnotetext{
70 Ibidem, 301-303.

${ }^{71}$ Ladero, 2008: 157

72 Ibidem, 157-158.

${ }^{73}$ Cédula real, Barcelona, 20 de mayo de 1519, AGI, I, 420, 1. 8, f. 62v.

74 Ladero, 2008: 158, 451.

${ }^{75}$ Declaración hecha por Juan López de Recalde, contador de la Casa de la Contratación, Toledo, 16 de diciembre de 1528, AGI, Justicia, 988, N. 3, R. 1.
} 
tratación, Juan López de Recalde, hacia 1506 el brasil se habría llegado a vender en la Casa a 2.000 maravedís el quintal (5,3 ducados), pero después las ventas se estancaron

... porque se vendía poco por estar subido en tan subido presçio; para que más cantidad se despachase, porque el brasil de Portugal que es mejor lo vendían en Portugal a dos e a tres ducados el quintal, y metían desde Portugal escondidamente el dicho brasyl en Castilla porque hera más rico en tintas que no el de las Yndias, e se vendía la mitad menos de lo que acá valía en el dicho Portugal ${ }^{76}$.

Parece evidente que el palo brasil traído por los portugueses ganó rápidamente la partida al comercializado por los españoles tanto por su calidad como por su precio, y que el cierre del mercado español decretado por los Reyes Católicos en 1503 se reveló finalmente incapaz de impedir la entrada de aquel en sus reinos. El potente mercader burgalés Juan Fernández de Castro, del que luego trataremos, confirmaba este balance cuando declaraba en 1528 que el quintal de brasil «no vale a dos ducados, y si no fuese por la prohibición ni valdría a uno ni aun tanto, porque en Flandes de lo bueno de Portugal vale a ducado y medio ${ }^{77}$. Los pleitos conservados en el Archivo de la Chancillería de Valladolid para 1518-1523 sobre incumplimiento de la pragmática de 1503 dan fe de la entrada ilegal del palo brasil portugués de manera continuada durante años hasta ciudades tan alejadas de la frontera como Soria ${ }^{78}$. Se trató de una realidad muy extendida. En 1511, al año siguiente de haberse reafirmado la pragmática de 1503 y haberse pregonado por toda Castilla, Fernando el Católico se veía obligado a ordenar al corregidor de Medina del Campo que hiciese averiguación sobre el brasil ilegal que había entrado en la villa porque «algunas personas sin temor de las penas [...] an metido a esta dicha villa de Medina del Campo e a otras partes mucho brasyl de fuera de los dichos reynos, de las partes que están vedadas e proyvidas ${ }^{79}$. Evidentemente, la introducción del brasil portugués en Medina del Campo perseguía su distribución por toda Castilla dada su función de centro comercial y financiero de referencia en el reino. Los mismos mercaderes genoveses parecen haberse decantado también por el brasil portugués. De 1513 se tiene noticia del envío (por Juan de Odón y Juan Bautista de Grimaldo «de la compañía de Agustín de Vivaldo») de importantes cantidades de este desde Portugal

76 Idem.

77 Su declaración en Declaración hecha por Juan López de Recalde, contador de la Casa de la Contratación, Toledo, 13-XII-1528, AGI, Justicia, 988, N. 3, R. 1.

78 Archivo de la Real Chancillería de Valladolid, Valladolid (ARChV), Pleitos Civiles, Pérez Alonso (F), caja 855, 3. ARChV, Registro de Ejecutorias, caja 363, 69.

${ }^{79}$ AGI, I, 418, 1. 3, f. 118r-v. 
hacia Génova por vía marítima; en este caso, la ciudad de Cádiz y los mercaderes Leonardo y Visconte Cataño debían servir simplemente para cambiar el producto de unos barcos a otros ${ }^{80}$.

Algunos documentos de finales de la segunda década del Quinientos señalan diferentes vías de comercialización del brasil desde la Casa de la Contratación, lo que apunta una continuación de su comercio en España a pesar de la crisis evidente. Así por ejemplo, en 1517, los mercaderes Pedro Fernández de Toledo, vecino de Sevilla, y Juan del Sueldo, vecino de Toledo, adquirieron brasil de la Casa por valor de 31.905 maravedís $^{81}$, indicando la participación de mercaderes sevillanos y toledanos vinculados con la industria textil en el suministro de brasil a la misma; también al puerto de Málaga habría llegado el brasil americano en esos primeros años del Quinientos ${ }^{82}$.

En los mercados del norte de Europa, y a pesar de los iniciales envíos a Flandes desde la Casa de la Contratación de Sevilla, el palo brasil portugués se impuso claramente, lo que no significa que no llegase también allí el de las Indias españolas. Los registros aduaneros del puerto de Bristol de 1503 y 1504 documentan la llegada de brasil americano, transportado principalmente por portugueses, y al menos en el caso de un navío, directamente desde Lisboa; la ruta muestra la reexpedición de una parte de ese brasil desde Bristol hacia Irlanda ${ }^{83}$. Por supuesto, también llegaba a Bristol el palo brasil desde España (así lo muestran los registros de 1512-1513), al igual que lo hacía la orchilla (se conocen datos sobre ello relativos a los años 1503-1504 y 15171518 , por ejemplo) ${ }^{84}$. En 1519, el mercader inglés Thomas Mallard, que operaba en Sevilla ${ }^{85}$, consiguió autorización de la Casa de la Contratación para sacar del reino 13 quintales y 29 libras de brasil que había comprado previa-

${ }_{80}$ Mojados, 19 de abril de 1513, AGI, I, 419, 1. 4, f. 109r-v.

${ }^{81}$ Catálogo de los fondos americanos..., 2002, vol. IV, doc. 511, Sevilla, 12-V-1517.

${ }^{82}$ En este sentido apuntan el hecho de que se conserve en su archivo municipal una copia de la pragmática de 1503 de la reina Isabel sobre el palo brasil (Pérez de Colosía y Gil Sanjuán 1978: 585) y que fuese uno de los productos listados entre los que debían pagar aranceles en la ciudad, por más que no se hayan podido documentar ventas del mismo en ella durante esta época de principios del siglo XVI (López Beltrán, 1986: 126).

${ }^{83}$ Maneuvrier, Daeffler y Bretthauer, 2018: 208-209. Quizás fuese precisamente el interés existente en Bristol por el palo brasil uno de los motivos de la expedición que en 1480 partió de este puerto en busca de la legendaria isla de Brasil, situada tradicionalmente en el Atlántico (The overseas trade of Bristol in the later Middle Ages, Bristol, 1937, vol. VII: 156-158, 161, 163-164). En los años noventa del siglo XV volvieron a salir de Bristol numerosos barcos «a buscar la isla del Brasil y las siete ciudades» (Medina, 1908, vol. I: 11). También Connell-Smith, 1954: 48.

${ }^{84}$ Connell-Smith, 1954: 210-212.

${ }^{85}$ Sobre este, Gil, 2001, vol. IV: 395. 
mente ${ }^{86}$, pensamos que seguramente para destinarlo a Inglaterra. La presencia en Sevilla de aquel veneciano de Bristol que fue Sebastián Caboto, que mantuvo relaciones con el mismo Mallard y otros ingleses de la Baja Andalucía ${ }^{87}$, puede ser un indicio más del interés inglés por el brasil y otros productos americanos. Además, los ingleses practicaron la piratería para hacerse con cargamentos de brasil. En 1513 un navío de Bergen-op-Zoom procedente de Lisboa con 17 toneladas y media de brasil fue apresado por los ingleses cuando se dirigía a Brabante y Flandes ${ }^{88}$. Por su parte, Fernández de Oviedo da la noticia de un corsario inglés que en 1527 «vino con una grande nao la vuelta del Brasil en la costa de la Tierra Firme, e de allí atravesó a esta isla Española» ${ }^{89}$.

Finalmente, los franceses también se interesaron desde muy pronto por el palo brasil americano. Ya Noronha, el primer arrendador del palo brasil portugués, se asoció con ellos para su explotación en los primeros años del siglo ${ }^{90}$. El interés de los centros industriales franceses por el brasil de las Indias era evidente. En Rouen, su demanda de palo brasil y de madera roja se desarrolló al calor de las necesidades de sus drapiers para la tintura de los paños de color escarlata ${ }^{91}$. En los primeros años del siglo XVI, los normandos recurrieron al corsarismo para arrebatar cargamentos de palo brasil a portugueses y españoles ${ }^{92}$. Tradicionalmente se ha sostenido que fue fundamentalmente a partir de 1526-1527 cuando los normandos comenzaron a organizar expediciones a las costas de Brasil y que, gracias a los viajes de Giovanni da Verrazano $(\dagger 1528)$ y de su hermano Girolamo en 1529 , acabaron abriendo una ruta directa desde los puertos normandos (Havre, Dieppe, Honfleur, Rouen), que sería transitada desde entonces y que alarmó de inmediato a los portugueses por lo que representaba de seria amenaza para sus pretensiones sobre las costas brasileñas ${ }^{93}$. No obstante, recientemente se ha sostenido a la luz del análisis de nueva documentación que la presencia de naves normandas en las costas brasileñas en busca de la preciada madera puede haber sido infraestimada y debería adelantarse a los primeros años del siglo $\mathrm{XVI}^{94}$. Sea como

${ }^{86}$ Catálogo de los fondos americanos..., 1990, vol. VII, doc. 1360, Sevilla, 8-IV-1519.

87 Gil, 1988: 12. En 1516, en Sevilla, Mallard prestó a Sebastián Caboto, «inglés», 55 ducados de oro (Catálogo de los fondos americanos..., 1930, vol. I: 490-491).

${ }^{88}$ Doehaerd, 1962, vol. III: 74.

89 Fernández de Oviedo, 1851, tomo I: 611.

${ }^{90}$ Pérez de Colosía y Gil Sanjuán, 1978: 586.

${ }_{91}$ Mollat, 1952: 256.

92 Ibidem: 251-252.

93 Ibidem: 252-256.

94 Maneuvrier, Daeffler y Bretthauer, 2018. 
fuere, lo cierto es que la comunidad de mercaderes españoles establecida en Rouen jugó un papel decisivo impulsando la importación de brasil desde los territorios que entraban en la demarcación de Portugal según el tratado de Tordesillas. En Honfleur, en 1529, se descargaron alrededor de 200 toneladas de madera roja traída directamente del Brasil por cuenta casi exclusiva de varios mercaderes de Rouen, a saber, Jean de Saldaigne (Saldaña), Jean de Quintanadoines (Quintanadueñas), Jean Postel, Jean Cavelier y Charles Mignot $^{95}$. También encontramos a los hermanos Jacques y Alonce de Civille (Sevilla) (burgaleses según Basas) ${ }^{96}$ y al bilbaíno Pedro de Salazar ${ }^{97}$. La nómina de estos mercaderes, encabezada por dos burgaleses de primera magnitud como Quintanadueñas y Saldaña, nos pone sobre aviso de la transformación radical que se estaba operando rápidamente durante la década de 1520 en el mercado internacional del brasil americano. Los mercaderes burgaleses, conscientes de las oportunidades de negocio que el brasil abría, se lanzaron desde los centros mercantiles europeos en los que operaban al intento de controlarlo de forma absoluta a fin de reforzar su posición clave en relación con el sector textil de Europa occidental, diversificando aún más los pilares de una preponderancia basada hasta entonces en el suministro tanto de la lana castellana como del pastel tolosano y de las islas atlánticas ${ }^{98}$.

\section{LOS HOMBRES DE NEGOCIOS BURGALESES Y EL MONOPOLIO DEL BRASIL DE LAS INDIAS DE CASTILLA, 1519-1530}

Tanto la crisis de las ventas del brasil de la Casa de la Contratación, como el cambio de política económica que se produce en el contexto de la primera venida de Carlos I a España, se hallan en el origen de la apertura del negocio a los grandes mercaderes burgaleses. Ya nos hemos referido a la orden de mayo de 1519 ordenando a la Casa de la Contratación buscar «personas» que comprasen las existencias y se hiciesen cargo de las ventas, y a la entrega unos meses más tarde de 40 quintales de brasil a Cristóbal de Haro, el principal promotor de la expedición de Magallanes a la Especiería y que ya en 1513-1514 había invertido en una expedición a la costa de Brasil que regresó

${ }_{95}$ Mollat, 1952: 257. Sobre el lugar de Juan de Quintanadueñas en su familia y en el marco de los negocios burgaleses, véanse Basas Fernández, 1960-1961a: 561-576; 1960$1961 b$.

96 Basas Fernández, 1960-1961b: 445. La hija de Alonso de Sevilla habría casado además con ese Juan de Quintanadueñas.

${ }_{97}$ Maneuvrier, Daeffler y Bretthauer, 2018: 195-196.

${ }_{98}$ Entre otros, véanse: Casado Alonso, 1991; 2005. Brumont, 1994. 
con un cargamento de palo brasil, además de esclavos ${ }^{99}$. El motivo de aquella orden no era otro que relanzar las ventas del brasil procedente de las Indias de Castilla. En la cédula real, el monarca señalaba a los oficiales de la Casa de la Contratación que «yo he mandado a Cristoval de Haro mercader vesino de la çibdad de Burgos que entienda en vender e haser despachar el brasyl que en essa casa ay nuestro, e para començar a entender en ello ha menester alguna cantidad de ello para enbiar a Flandes e a otras partes» ${ }^{100}$.

Lo cierto es que durante los años siguientes diversos documentos se refieren a la extrema escasez de las existencias de brasil de la Casa, lo que facilitó la concesión de mercedes reales para importarlo desde Portugal a pesar de la vigencia de la pragmática de 1503. El mismo Cristóbal de Haro consiguió en 1522 permiso de la corona para introducir por tierra 1.500 quintales de brasil desde Portugal en Castilla, atendiendo a que «al presente no ay brasil nuestro en la nuestra Casa de la Contratación de las Yndias» ${ }^{101}$. Aunque existen noticias de llegadas de brasil a la Casa de la Contratación en estos años ${ }^{102}$, lo cierto es que la escasez continuaba. La merced hecha a Ruy Sánchez de Toledo, contino del rey, revela cuál era la situación en 1526. Por una cédula dada en agosto de ese año se le permitió meter en Castilla 400 quintales de brasil que tenía en Portugal, siempre que antes comprase otros tantos en la Casa de la Contratación al precio que concertare con ésta ${ }^{103}$; sin embargo, la Casa sólo disponía de 90 quintales almacenados, por los que una nueva cédula hubo de rebajar la exigencia de compra hasta esta cantidad ${ }^{104}$. Su merced no fue la única. El mercader Bartolomé de Castro, vecino de Lisboa y criado de la reina de Portugal (Catalina de Austria, hermana de Carlos V), también obtuvo en abril de 1527 una licencia para introducir en Castilla otros 250 quintales de brasil que el monarca João III le había facilitado en Portugal; para su distribución en Castilla recurrió a tres mercaderes de Medina del Campo ${ }^{105}$.

99 Ramos Pérez, 1992: 139.

100 Barcelona, 30 de marzo de 1519, AGI, I, 420, 1. 8, f. 51v.

101 La cédula real está datada en Vitoria a 27 de mayo de 1522, y fue confirmada por otra de Valladolid a 5 de junio de 1523 (AGI, I, 420, 1. 9, f. 142v-143v). Hay una copia de esta última incluida en AGI, Justicia, 988, N. 3, R. 1.

102 De 1525, por ejemplo (Catálogo de los fondos americanos..., 1937, vol. V, doc. 973).

103 Granada, 31 de agosto de 1526, AGI, I, 421, 1. 11, f. 142r-v.

104 Cédula real, Valladolid, 6 de abril de 1527, AGI, I, 421, 1. 12, f. 62r-v. La cédula autorizando la venta a Sánchez de Toledo de los 90 quintales es de Burgos a 29 de noviembre de 1527 (AGI, I, 421, 1. 12, f. 235v-236r).

${ }^{105}$ Cédula real, Valladolid, 6 de abril de 1527, AGI, I, 421, 1. 12, f. 61r. Copia de la misma y del poder de Bartolomé de Castro a los mercaderes Francisco de Medina, García de Vega y Pedro de Medina, vecinos de Medina del Campo, AGI, Justicia, 988, N. 3, R. 1. 
Antes que ellos, en noviembre de 1525, el burgalés García de Lerma, hombre con amplia experiencia americana y auténtico conseguidor en la corte ${ }^{106}$, obtuvo licencia para cortar en el plazo de dos años 6.000 quintales de palo brasil en las islas Española y Saona o en cualquier parte de las Indias y traerlo a España, pagando por cada quintal dos reales (68 maravedís). Lerma no era más que un intermediario, pues enseguida traspasó el negocio: en 14 de febrero de 1526 cedió 500 quintales de su merced a Diego de Aranda, burgalés de Sevilla, por precio de 200 ducados, quien enseguida encargó las tareas oportunas a Melchor de Castro, vecino y escribano de minas en Santo Domingo; asimismo, en 27 de marzo de 1526 Lerma vendió el derecho de cortar otros 4.100 quintales de brasil por precio de 500 ducados a una sociedad compuesta por el mismo Diego de Aranda, Melchor de Castro y otro burgalés, Diego Díaz, reservándose además la cuarta parte de los beneficios que rindiesen 4.000 quintales ${ }^{107}$. No obstante, éstos toparon enseguida con la dificultad de conseguir cortar el palo brasil en las Indias, puesto que la escasez en el abastecimiento también se debía a agudos problemas para acceder a nuevas regiones donde se conservasen los árboles.

Este intento por reactivar el comercio del brasil desde el Caribe hacia España no hizo sino reanudar la pugna por su control. En 8 de junio de 1526, el rey firmó un asiento con otro poderoso mercader burgalés de Sevilla, Juan Fernández de Castro, para la corta y traída del palo brasil desde las Indias. Según este acuerdo ${ }^{108}$, Fernández de Castro y sus herederos disfrutarían durante treinta años del monopolio de la corta e importación del palo desde las Indias de Castilla, obligándose a repartir los beneficios con la corona ${ }^{109}$, a traer cargado al menos un navío de 60 toneladas al año y a almacenar el brasil en las atarazanas de Sevilla; al final del periodo de treinta años, él o sus herederos conservarían el derecho a seguir importando 400 quintales de brasil limpio cada año, del que deberían entregar una tercera parte a la corona. No obstante, el contrato dejaba abierto un plazo de diez meses para que otros hombres de negocios pudieran mejorar a la corona las condiciones de dicho contrato, de modo que no sería hasta abril de 1527 cuando entraría en vigor. Y así sucedió. En 29 de marzo de 1527, el Consejo de Indias informaba a Juan

106 Martín Acosta, 1994: 39-52.

107 Otte, 1977: 278-279. La cédula a favor de García de Lerma está datada a 24 de noviembre de 1525. Sobre Diego Díaz, véase Pérez García, 2020.

108 Asiento del brasil, Granada, 8 de junio de 1526, AGI, I, 421, 1.11, f. 15r-17r.

109 En su preámbulo, el asiento especifica que los beneficios se repartirán por partes iguales entre Juan Fernández de Castro y la corona, pero después aclara que el brasil limpio se repartiría de la siguiente manera: un tercio para el rey y dos tercios para Juan Fernández de Castro o sus herederos. 
Fernández de Castro que otras personas habían pujado ofreciendo «dos quintos más que vos», por si estaba dispuesto a mejorar su oferta ${ }^{110}$. De nuevo, en 1 de junio se le volvió a notificar otra mejora en la puja por parte de un tercero, ofreciéndole un plazo de veinte días para realizar una apuesta mejor ${ }^{111}$. Finalmente, Juan Fernández de Castro se hizo con el monopolio del brasil mediante otro asiento firmado con la corona el 29 de noviembre de 1527, solo que ahora las cantidades de brasil a entregar a la corona habían pasado de un tercio $(33,3 \%)$ a dos quintas partes (40\%), y que compartiría dicho monopolio con Juan de Ampiés, vecino y factor de La Española ${ }^{112}$. La inclusión de Ampiés en el asiento tenía como objeto, precisamente, salvar el inconveniente de la dificultad de acceder a zonas que conservasen reservas de palo brasil.

En efecto, durante esos años Ampiés ${ }^{113}$ se había convertido, supuestamente, en una pieza clave para la corta del brasil en el área del Caribe. Factor de la isla Española desde $1511^{114}$ y regidor de la ciudad de Santo Domingo, a pesar de estar rodeado de una oscura reputación ${ }^{115}$ de corrupción ${ }^{116}$ y malos tratos ${ }^{117}$ conservaba en esas fechas la plena confianza del Consejo de Indias para los asuntos americanos $^{118}$. En noviembre de 1525 obtuvo de la corona la confirmación de la posesión en exclusiva de las islas de Curaçao, Aruba y Bonaire y la encomienda de sus indios, que al parecer ya le dieran en su día los frailes jerónimos y el licenciado Rodrigo de Figueroa ${ }^{119}$; al año siguiente se le entregó el documento

110 Cédula real, Valladolid, 29 de marzo de 1527, AGI, I, 421, 1. 12, f. 51v-52r.

111 Cédula real, Valladolid, 1 de junio de 1527, AGI, I, 421, 1. 12, f. 111r.

112 Asiento sobre el brasil, Burgos, 29 de noviembre de 1527, AGI, I, 421, 1. 12, f. 240v$241 \mathrm{v}$.

113 El personaje ha sido estudiado con detenimiento por Ramos, 1978.

114 AGI, I, 418, 1. 3, f. 94r-v.

115 Ramos, 1978: 192-196, habla de «campaña contra la fiabilidad de Ampiés».

116 Véase la demoledora cédula de 4 de agosto de 1525 publicada en Otte, 1963: 157-160.

117 Su mujer, doña Florencia, obtuvo del obispo Alexandrino la separación de su marido hacia 1523, pasando a residir en casa de su hermano el contador Alonso de Ávila, a causa de los malos tratos que Ampiés le daba: «por yndusimiento de una criada naboría yndia que el dicho su marido tiene en casa le da muy mala vida y la trata mal poniendo en ella las manos muy aydaramente [sic] y algunas vezes poniéndole un puñal en los pechos para la matar», habiendo intentado incluso envenenarla con «yerbas e bebedizos por mano de la dicha yndia» (21 de agosto de 1528, AGI, I, 421, 1. 13, f. 312r-v).

118 Véase la recomendación que de él se hace en la cédula de 1-III-1527 al licenciado Vadillo: «es persona que ha mucho tienpo que nos sirve en esas partes por lo qual y por ser deudo de criados y servidores nuestros tengo voluntad de le mandar favorecer y hazer merçed» (AGI, I, 421, 1. 12, f. 26v).

119 Otte, 1963: 161-162, doc. 97. Aunque lo referente a los jerónimos parece que en realidad no pasara de una mera propuesta (Ramos, 1978: 64-65, 126); para lo relacionado con Figueroa, Ramos, 1978: 137-146. 
del requerimiento que debería leer a los habitantes de dichas islas para exigir su obediencia, paso formal previo a una toma oficial de posesión ${ }^{120}$. Desde 15211522 aproximadamente, Gonzalo de Sevilla en su nombre había intentado hacer efectivo su dominio en las islas cristianizando a algunos de sus habitantes y oponiéndose judicialmente a las armadas de rescate que los esclavizaban ilegalmente $^{121}$. Finalmente, en 15 de noviembre de 1526 Ampiés consiguió una cédula real del Consejo de Indias que le confirmaba una licencia anterior dada por el almirante Diego Colón para «tener y poblar» las islas de Curaçao, Aruba y Bonaire, en la «comarca de la Tierra Firme llamada Castilla del Oro», además de poder «contratar e rescatar con el dicho caçique de Coro» ${ }^{122}$. Llamativamente, esta concesión hecha de forma limitada (no se especificaba su término, pues sólo sería válida hasta que la corona determinase algo distinto y Ampiés había de informar en el plazo de diez meses sobre el hallazgo de oro, plata, perlas u «otras cosas»), establecía la obligatoriedad de cumplir con las Ordenanzas de Granada de 17 de noviembre de 1526 (datadas dos días después) sobre el buen tratamiento de los indios y manera de hacer nuevas conquistas ${ }^{123}$. Ello impedía esclavizar a los indios, lo cual no era un verdadero problema dado que ahora el interés no era otro que la corta del palo brasil tanto en las islas como en la costa venezolana, en la zona de Coro. En efecto, en aquella primavera y verano de 1527, mientras en Castilla continuaban las pujas por el asiento del brasil, se organizaba la operación que lo podría materializar a gran escala. En mayo de 1527 Ampiés consiguió el permiso real para salir de La Española y dejar de ejercer su oficio de factor en la isla ${ }^{124}$, y en 26 de julio se habría producido la fundación de Coro, tradicionalmente atribuida a Ampiés, a fin de explotar el palo brasil de la región de la costa venezolana ${ }^{125}$. Las fechas no son casuales, pues de cuatro días más tarde, 30 de julio de 1527, data el concierto de Ampiés con Melchor de Castro, Diego de Aranda, Diego Díaz y García de Lerma para llevar a efecto la corta de 4.500 quintales correspondientes a la licencia de los 6.000 quintales de brasil y transportarlo hasta Santo Domingo ${ }^{126}$, y el mismo Juan Fernández de

${ }^{120}$ El requerimiento se conserva en AGI, Panamá, 233, 1. 2, f. 219v-221v.

121 Otte, 1963: 162-166, doc. 98. Ramos, 1978: 163-167, 176-191, que sitúa la ida de Gonzalo de Sevilla a Curaçao en marzo de 1522.

122 Granada, 15 de noviembre de 1526, AGI, I, 415, 1. 1, f. 105v-111v. También en Otte, 1963: 186-188, doc. 118.

${ }^{123}$ El texto de las mismas, transcrito íntegro en el documento anterior (AGI, I, 415, 1. 1, f. 105v-111v), ha sido publicado varias veces, también en Morales Padrón, 2008: 374-379.

124 Otte, 1963: 226-227, doc. 136.

125 Friede, 1961: 176, que discute que la fundación la llevase a cabo efectivamente Ampiés. Ramos, 1978: 289-290, defiende que la fundación la hizo el hijo de Ampiés.

126 Otte, 1977: 281. 
Castro cerró el trato con Ampiés durante aquellos meses para sacar adelante el negocio del brasil ${ }^{127}$. Para los beneficiarios de la merced de García de Lerma, se trataba en realidad de su última oportunidad para beneficiarse de ella dado que, a pesar de dos prórrogas sucesivas que sumaron 18 meses y que extendieron su validez hasta junio o julio de 1528 , su término estaba próximo ${ }^{128}$. No obstante, el enfrentamiento de Ampiés con los alemanes que actuaban desde 1528 en representación de los Welser en Venezuela impidió, de hecho, la corta y transporte del palo brasil a la ciudad de Santo Domingo, lo que no solo acabó dejando sin aplicación la licencia de 4.500 quintales de que disfrutaba el grupo CastroAranda-Díaz al terminar su periodo de ejecución ${ }^{129}$, sino que también impidió a Ampiés y a Juan Fernández de Castro hacer frente al compromiso adquirido con la corona para ese año de 1528, en el que no entregaron las cantidades acordadas de brasil, a pesar de lo cual existen datos de que trabajaron en ello. En julio de aquel año, Juan Fernández de Castro encargaba desde Sevilla a Gonzalo Núñez y a Ochoa de Barriga que ordenasen cortar el brasil y lo transportasen al puerto de Santo Domingo para remitirlo a Sevilla en las naos que fuesen necesarias ${ }^{130}$. La misma corona no dudaba del cumplimiento del asiento, cuando en el verano el rey ordenaba a Ampiés y a Juan Fernández de Castro, en virtud del asiento firmado, y a García de Lerma a causa de la licencia de los 6.000 quintales de brasil, que entregasen 300 ducados, de la parte que le correspondía al Rey, a su «tía» doña María de Aragón, para ayuda a la obra del monasterio de Madrigal del que era priora ${ }^{131}$.

127 Catálogo de los fondos americanos..., 1986, vol. VI, doc. 291. En 24-IX-1527, Fernández de Castro dio un poder a Antonio Sedeño, contador de la isla de San Juan que estaba en la corte, para que en su nombre concertase con un delegado de Ampiés el negocio del brasil que tenían pendiente de cerrar.

128 AGI, I, 421, 1. 12, f. 234v-235r. Por cédula de Granada de 8 de diciembre de 1526 su duración se prorrogó por un año más, y por otra dada en Burgos a 29 de noviembre de 1527, por otros seis meses más.

129 El incumplimiento por parte de Ampiés de entregar los 4.500 quintales de brasil en el plazo de 15 ó 16 meses a partir de la firma del contrato, motivó una reclamación judicial en 1529 por parte de Melchor de Castro, Diego de Aranda y Diego Díaz ante la audiencia de Santo Domingo. En este proceso judicial, que todavía seguía abierto en 1533, éstos reclamaron que el incumplimiento por parte de Ampiés se había debido a una dejación de sus obligaciones. Sin embargo, Ampiés se defendió alegando que todo se debió a la prohibición dictada por la propia audiencia de abandonar La Española para dirigirse a Venezuela, ante el temor de que invadiese la esfera de competencia que Carlos I había otorgado allí a los alemanes (AGI, Justicia, 5, N. 5).

${ }^{130}$ Catálogo de los fondos americanos..., 1986, vol. VI, doc. 551, Sevilla, 27-VII-1528.

131 Monzón, 5 de junio de 1528, AGI, I, 421, 1. 13, f. 130v-131r. María de Aragón era hija ilegítima de Fernando el Católico, monja agustina en el convento de Nuestra Señora de Gracia de Madrigal de las Altas Torres, y mantuvo excelentes relaciones con Carlos I y la emperatriz Isabel; tras su muerte fue enterrada allí en 1535 (Parrado del Olmo y Payo Hernanz, 2016: 3-21). 
Finalmente Ampiés y Fernández de Castro no cumplieron ese año de 1528 con sus obligaciones respecto a la corona, por lo que el fiscal del Consejo de Indias movió dos pleitos contra ellos, uno para conseguir la «disolución» del asiento $^{132}$ y otro para obtener una compensación a favor de la hacienda regia por los daños recibidos ${ }^{133}$ y por el que fueron condenados cada uno de ellos a pagar 220.000 maravedís en el plazo de 200 días desde la notificación de la sentencia ${ }^{134}$. No obstante, varios meses antes de la conclusión de este último pleito, Ampiés y Fernández de Castro llevaron a cabo una renegociación del asiento aprovechando las apreturas económicas de Carlos I a causa de la guerra en Europa. En virtud del nuevo acuerdo al que se llegó (de febrero de 1529), que modificaba los términos del asiento anterior, ambos mercaderes sustituirían la entrega de las dos quintas partes del brasil por el pago de una cantidad anual de 250.000 maravedís con la que a su vez comprarían «la tal cantidad al quitar a razón de quinze mill el millar», lo que significó la adquisición de un juro al quitar por valor de 3.750 .000 maravedís a un interés anual del 6,666 \%; tan importante cantidad se satisfaría a la hacienda regia en tres pagas sucesivas «en ducados contados» de 1.500 .000 maravedís, 1.125 .000 y 1.125.000 maravedís en las ferias de Medina del Campo (de 21-VI-1529 y en la feria de octubre) y de Villalón (de 1530) ${ }^{135}$. De este modo, desde 1529 Juan de Ampiés y Juan Fernández de Castro disfrutaron de un monopolio sobre la totalidad del brasil extraído de las Indias españolas. Por si acaso, varias cédulas reales de 1531 ordenaron a García de Lerma y a los demás gobernadores de las Indias que dejasen a Ampiés y a sus empleados cortar el brasil y traerlo a España en virtud del asiento que ya conocemos ${ }^{136}$.

Los datos anteriores nos permiten conocer cómo diversos mercaderes burgaleses que operaban en Sevilla pugnaron por hacerse con el control del palo brasil del Caribe. Sus nombres apuntan directamente a la cúpula de la comunidad burgalesa de Sevilla. Juan de Aranda fue quien introdujo a Magallanes en la corte, servicio que le valió el cargo de factor de la Casa de la Contratación; gracias a su casamiento en Sevilla con Ana Pérez Cisbón, emparentó con la riquísima élite conversa sevillana, absolutamente involucrada en los

132 AGI, Justicia, 988, N. 3, R. 1.

133 AGI, Justicia, 987, N. 3, R. 2.

134 Madrid, 27 de octubre de 1529, AGI, Patronato, 276, N. 3, R. 12.

135 Toledo, 17 de febrero de 1529, AGI, Patronato, 170, R. 36. El rey se comprometía a entregarles «la premática que está hecha para que no entre brasil de fuera parte ni otra persona lo pueda vender en nuestros reynos», reafirmando así el monopolio sobre el brasil de Ampiés y Fernández de Castro. En cuanto al pleito que se desarrollaba en el Consejo de Indias por los impagos de 1528, la corona no renunciaba a las compensaciones que pudieran tener lugar.

${ }^{136}$ Ocaña, 4 de abril de 1531 y 10 de mayo de 1531, AGI, Santa Fe, 1174, 1. 1, f. 69v y 75v. 
negocios del Caribe ${ }^{137}$. Diego Díaz, otro mercader burgalés establecido en Sevilla al calor de la expedición de Magallanes, fue el hombre en Sevilla del gran capitalista burgalés Cristóbal de Haro, principal promotor de aquel viaje, y agente en la ciudad de los Fugger ${ }^{138}$, vinculado también con los Welser ${ }^{139}$ e interesado asimismo en el palo brasil. Por su parte, Melchor de Castro fue un importante funcionario de La Española durante la primera mitad del siglo $\mathrm{XVI}^{140}$ que aprovechó su posición en la isla para desarrollar diferentes nego$\operatorname{cios}^{141}$. Su relación con Diego Díaz era fundamental, puesto que este era el responsable de recibir en Sevilla cuanto llegase consignado a su nombre desde las Indias a la ciudad, además de cobrar sus deudas en ella ${ }^{142}$.

Finalmente, Juan Fernández de Castro, que se hizo con el monopolio de la explotación del palo brasil en las Indias españolas, era uno de los más importantes capitalistas burgaleses que operaban en Sevilla en aquella época, con un perfil de negocio claramente diferenciado respecto del de la mayoría de burgaleses que operaban en la ciudad como importadores de textiles del

137 Gil, 2001, vol. III: 518. Pérez García, 2018: 619-620.

138 Pérez García, 2020.

139 Otte, 1977: 282.

${ }_{140}$ Vecino en Indias desde 1508 (AGI, I, 1961, 1. 1, f. 103v), escribano mayor de minas de La Española desde 1519 (AGI, I, 420, 1. 8, f. 33r-34r), disfrutó de tierras, ganados e indios encomendados en la isla (AGI, I, 420, 1. 8, f. 114v-115r; AGI, Indiferente, 421, 1. 13, f. 141v). Se trataba de una figura clave de la administración de la isla, puesto que debido a su cargo, todo el oro que salía de la misma debía pasar por sus manos (Sevilla, 22 de octubre de 1525, AGI, I, 420, 1. 10, f. 124r-v.), como también la fiscalización de los registros de mercancías de las naos en su viaje de regreso a la Península Ibérica (Catálogo de los fondos americanos..., 1986, vol. VI, doc. 1007, Sevilla, 1-XII-1529). Su progreso económico y social le llevó a realizar en 1535 una probanza de testigos en la ciudad de Santo Domingo para que se le concediesen privilegios de hidalguía por sus servicios a la corona (AGI, Justicia, 1003, N. 5, R. 2). Seguía vivo en 1541 (AGI, Santo Domingo, 868, 1. 2, f. 43v). Finalmente renunció a su oficio de escribano de minas en favor de su sobrino Pedro de Castro, hijo de su hermano Gaspar de Castro (factor de la isla de San Juan de Puerto Rico) y de la esposa de este, doña Catalina Maldonado (AGI, Santo Domingo, 899, 1. 1, f. 118).

${ }^{141}$ Es bastante probable que su asentamiento en la isla se produjese precisamente para desarrollar el comercio (Catálogo de los fondos americanos..., 1990, vol. VII, doc. 715, Sevilla, 10-V-1511). Sobre su actividad mercantil durante la década de 1510, véase Catálogo de los fondos americanos..., 1930, vol. I: docs. 778, 840, 888, 916, 1077, 1176, 1197. Evidentemente, dado su cargo, prestó los típicos servicios financieros en La Española para diversos mercaderes. En 1539, por ejemplo, Alonso Gómez de la Serna, mercader burgalés vecino de Sevilla, le apoderaba para cobrar allí las deudas que le debieren. Véase Sevilla, 31 de diciembre de 1539, Archivo Histórico Provincial de Sevilla, Sevilla (AHPSe), Protocolos Notariales de Sevilla, leg. 3336.

142 Catálogo de los fondos americanos..., 1937, vol. V, doc. 1047, Sevilla, 24-III-1526. 
norte de Europa ${ }^{143}$, especializado en grandes inversiones, como la trata negrera hacia América a gran escala, de la que fue uno de sus fundadores ${ }^{144}$, o la promoción de la minería del oro, campo en el que también intentó ocupar un lugar central en $1526^{145}$. Su hijo Fernando de Castro casaría precisamente con una hija de Juan de Aranda, Juana de Aranda, revelando los estrechos vínculos existentes entre ambos hombres ${ }^{146}$.

En la práctica, sin embargo, fueron Ampiés, que falleció en 1533, y Juan Fernández de Castro, quienes se hicieron en exclusiva con el monopolio del brasil, puesto que la sociedad formada por Diego Díaz, Diego de Aranda y Melchor de Castro todavía en febrero de 1536 reconocía no haber traído el brasil «por ciertos impedimentos que por parte de Su Majestad fueron puestos» y que «el término en que se avía de traer es pasado», por lo que encargaron a Aranda que solicitase del Consejo una prórroga ${ }^{147}$. Dado que Aranda falleció aquel mismo año, no pensamos que esta iniciativa tuviera efecto alguno.

Por su parte, durante la década de 1530, Juan Fernández de Castro, y a pesar de la disolución del asiento del brasil en 1537 por sentencia del Consejo de Indias ${ }^{148}$, consiguió ocupar un lugar central como monopolista del brasil americano, también del llegado a Portugal, del que introdujo cantidades masivas en Francia en aquella década ${ }^{149}$. Al menos de forma temporal, este representante de una de las principales familias de capitalistas burgaleses consiguió hacerse con el control efectivo de un producto cuyo interés no dejó de crecer para la industria textil europea, imponiéndose sobre otros mercaderes burgaleses e incluso otros grupos de hombres de negocios portugueses e italianos.

\section{Conclusiones}

En este trabajo se ha estudiado el proceso por el que determinadas empresas y mercaderes de origen burgalés consiguieron hacerse con el control de la importación y redistribución en Europa del palo brasil procedente de las

143 Pérez García, 2016.

144 Fernández Chaves y Pérez García, 2016: 388-396.

145 Granada, 20 de junio de 1526, AGI, I, 421, 1. 11, f. 41r-42r.

146 Pérez García, 2018: 621 y 623.

147 Sevilla, 22 de febrero de 1536, AHPSe, Protocolos Notariales de Sevilla, leg. 3314.

148 AGI, Justicia, 988, N. 3, R. 1.

149 Véase, por ejemplo, la Licencia a Juan Fernández de Castro para introducir palo brasil en Castilla, Toledo, 18 de abril de 1539, AGI, Indiferente, 423, 1. 19, f. 236v-237r. En este momento, Juan Fernández de Castro afirmaba tener en Francia 2.500 quintales de brasil procedente de la demarcación de Portugal. 
Indias de Castilla en el periodo fundacional de la nueva economía atlántica. Obviamente, los burgaleses también se introdujeron en el sistema imperial portugués para controlar la producción y comercialización del procedente de las costas de Brasil. Nuevas investigaciones deberán explicar con detalle la continuación de esta historia y la evolución de la demanda y consumo del palo brasil en los centros textiles europeos; se trata de una tarea pendiente. Sí se sabe que la escasa calidad del brasil venido de las Indias de Castilla y su escasez en el mercado español motivaron que en 1548 Carlos V autorizase finalmente la entrada del procedente del extranjero, es decir, del suministrado por los portugueses, fundamentalmente ${ }^{150}$, poniendo fin, definitivamente, al proyecto económico de los Reyes Católicos. Todavía a mediados del siglo XVI existía una significativa demanda de palo brasil en una ciudad industrial como Córdoba, y en la segunda mitad de esa centuria seguía presente en el mercado sevillano. De hecho las importaciones a Sevilla continuaron durante la época de Felipe II: en 1566 la corona disponía de 1.500 quintales almacenados en la ciudad, y en 1576, año en que las importaciones parecen haber llegado a su máximo, se recibieron en ella 1.728 quintales; el hecho de que su precio en la década de 1570 oscilase entre los 500 y 510 maravedís por quinta $^{151}$ (entre 1,33 y 1,36 ducados/quintal) revela claramente cómo su precio había continuado cayendo imparablemente desde principios del siglo. $\mathrm{Si}$ bien Mauro ha demostrado la importancia del palo brasil portugués en el periodo de la Unión Ibérica ${ }^{152}$, también es verdad que los índices económicos conocidos, como el de derechos fiscales cobrados por su introducción en Castilla para 1559-1591, insisten en que su importancia económica era secundaria habida cuenta de los ingresos que generaba ${ }^{153}$.

Sin duda, en el hecho de que el éxito del ciclo del palo brasil americano fuera tan breve influyó el desarrollo arrollador de la grana cochinilla americana desde la década de 1520 , con niveles de producción relevantes ya en la de 1550: se trataba de un producto netamente superior y que invadió sin resistencia los mercados europeos ${ }^{154}$. Resulta evidente que la puesta en explotación del continente americano causó profundas transformaciones en la industria textil europea. El caso de las materias tintóreas es claro y los hombres de negocios que protagonizaron aquella primera expansión europea fueron siempre plenamente conscientes de las posibilidades económicas que abrían

\footnotetext{
${ }^{150}$ Lorenzo Sanz, 1979, tomo I: 599-600.

151 Ibidem: 600.

152 Mauro, 1997.

153 Ulloa, 1977: 297.

154 Lorenzo Sanz, 1979, tomo I: 548-588.
} 
las nuevas tierras. Jean Pierre Berthe ya señaló que no parecía una casualidad que al fracaso definitivo del cultivo del pastel en Jalapa, en Nueva España, en la década de 1550, sucediese de manera inmediata a partir de 1560 en esa misma región la identificación del añil o índigo como sustituto del mismo («en esa tierra ay una yerva o tierra que haze el mismo heffeto que el pastel»); a finales del Quinientos la crisis del pastel ya era evidente por la competencia del añi $1^{155}$. En cuanto al palo brasil, sobrevivió como un producto de interés secundario pero no carente de utilidad ni valor. En la segunda mitad del XVII, la producción de palo brasil seguía constituyendo una de las principales exportaciones portuguesas desde Brasi1 ${ }^{156}$, y en el siglo XVIII tanto el producido por los españoles en México y en Santa Marta como el brasileño de Pernambuco seguían afluyendo a Europa ${ }^{157}$.

\section{Bibliografía}

Alguns documentos do Archivo Nacional da Torre do Tombo áçerca das navegações e conquistas portuguezas, Lisboa, Imprensa Nacional, 1892.

Andrés Díaz, Rosana de, "La financiación «extraordinaria» de los viajes colombinos y de otros gastos de Indias: nuevas aportaciones documentales y nóminas de tripulantes y pasajeros", Boletín de la Real Academia de la Historia, 205 (Madrid, 2008): 393-460.

Arroyo Ilera, Rafael, "El palo del brasil en el descubrimiento del Nuevo Mundo", Argensola. Revista del Instituto de Estudios Altoaragoneses, 45 (Huesca, 1961): 145-146.

Azevedo, J. Lúcio de, Épocas de Portugal Económico, Porto, Clássica Editora, 1988.

Aznar Vallejo, Eduardo, "Navegación oceánica y expansión comercial”, Manuel González Jiménez (ed.), La Península Ibérica en la Era de los Descubrimientos (1391-1492). Actas III Jornadas Hispano-Portuguesas de Historia Medieval, Sevilla, Junta de Andalucía / Universidad de Sevilla, 1991, vol. 1: 343-370.

Basas Fernández, Manuel, "El mercader burgalés Gómez de Quintanadueñas", Boletín de la Institución Fernán González, 14 (Burgos, 1960-1961a): 561-576.

Basas Fernández, Manuel, "Mercaderes y corsarios en el siglo XVI", Boletín de la Institución Fernán González, 14 (Burgos, 1960-1961b): 442-453.

\footnotetext{
155 Berthe, 1960. Brumont, 1994: 36-39. Lorenzo Sanz, 1979, tomo I: 588-597.

156 Boxer, 2017: 155.

157 Cardon, 2016: 70.
} 
Bazant, Jan, "Evolution of the Textile Industry of Puebla, 1544-1845", Comparative Studies in Society and History, 7 (Cambridge, 1964): 56-69.

Belamaric, Josko, "Cloth and Geography: Town Planning and Architectural Aspects of the First Industry in Dubrovnick in the 15th Century", Alina Payne (ed.), Dalmatia and the Mediterranean. Portable Archaeology and the Poetics of Influence, Leiden / Boston, Brill, 2014: 268-309.

Bello León, Juan Manuel, "Notas para valorar la contribución de la expansión atlántica a la Hacienda real castellana a finales de la Edad Media”, Revista de Historia Canaria, 188 (La Laguna, 2006): 61-75.

Bello León, Juan Manuel, "Los negocios de los mercaderes Francesco Pinelli y Diego de Soria en el Atlántico medio a finales del siglo XV", Revista de Historia Canaria, 200 (La Laguna, 2018): 59-72.

Berthe, Jean-Pierre, "El cultivo del «pastel» en Nueva España", Historia mexicana, 9 (México, 1960): 340-367.

Boxer, Charles R., O Império marítimo português 1415-1825, Lisboa, Edições 70, 1997.

Brumont, Francis, "La commercialisation du pastel toulousain (1350-1600)", Annales du Midi, 106 (Toulouse, 1994): 25-40.

Carande, Ramón, "La navegación y el comercio en el Mediterráneo durante el siglo XVI", Estudios de Historia. 1. Temas de historia de España, Barcelona, Crítica, 1989: 321-366.

Cardon, Dominique, The Dyer's Handbook. Memoires of an 18th-Century Master Colorist, Oxford / Philadelphia, Oxbow Books, 2016.

“Cartas de quitação del Rei D. Manuel”, Archivo Historico Portuguez, 1 (Lisboa, 1903).

Casado Alonso, Hilario, "Comercio internacional y seguros marítimos en Burgos en la época de los Reyes Católicos", Congresso Internacional Bartolomeu Dias e a sua época. Actas, Porto, Universidade do Porto, 1989, vol. III: 585-608.

Casado Alonso, Hilario, "Finance et commerce international au milieu du XVIe siècle: la compagnie des Bernuy”, Annales du Midi, 103 (Toulouse, 1991): 323-343.

Casado Alonso, Hilario, "El papel de las colonias mercantiles castellanas de los Países Bajos en el eje comercial Flandes-Portugal e islas atlánticas", Bernardo J. García García y Fernando Grilo (coords.), Ao modo da Flandres. Disponibilidade, innovação e mercado de arte na época dos descobrimentos, Madrid, Fernando de Villaverde Ediciones, 2005: 17-35.

Catálogo de los fondos americanos del Archivo de Protocolos de Sevilla, Sevilla, Instituto Hispano-Cubano de Historia de América, 1930-2017, 14 vols. 
Colección de documentos inéditos relativos al descubrimiento, conquista y organización de las antiguas posesiones españolas de América y Oceanía, Madrid, Imprenta de Manuel G. Hernández, 1879, tomo 32.

Colón, Cristóbal, Los cuatro viajes. Testamento, Madrid, Alianza, 1986.

Connell-Smith, Gordon, Forerunners of Drake. A Study of English trade with Spain in the early Tudor period, London / New York / Toronto, Longmans, Green and Co., 1954.

Córdoba de la Llave, Ricardo, Los oficios medievales. Tecnología, producción, trabajo, Madrid, Síntesis, 2017.

Doehaerd, Renée, Études anversoises. Documents sur le commerce international à Anvers, París, SEVPEN, 1962, 3 vols.

Eberhard, Winfried, "La crisis de la Baja Edad Media: hacia una síntesis final", Ferdinand Seibt y Winfried Eberhard (eds.), Europa 1400. La crisis de la Baja Edad Media, Barcelona, Crítica, 1992: 246-267.

Fernández Chaves, Manuel F., "Antonio Faleiro de Acosta, mercader portugués de pastel en Sevilla, 1573-1583”, Juan José Iglesias Rodríguez y José Jaime García Bernal (eds.), Andalucía en el mundo atlántico moderno. Agentes y escenarios, Madrid, Sílex, 2016: 59-85.

Fernández Chaves, Manuel F. y Pérez García, Rafael M., "La élite mercantil judeoconversa andaluza y la articulación de la trata negrera hacia las Indias de Castilla, ca. 1518-1560", Hispania, 76 (Madrid, 2016): 385-414.

Fernández de Oviedo, Gonzalo, Historia General y Natural de las Indias, Madrid, Imprenta de la Real Academia de la Historia, 1851, tomo I.

Fortea Pérez, José Ignacio, Córdoba en el siglo XVI. Las bases demográficas y económicas de una expansión urbana, Córdoba, Caja de Ahorros de Córdoba, 1981.

Friede, Juan, Los Welser en la conquista de Venezuela, Caracas / Madrid, Ediciones EDIME, 1961.

Gil, Juan, "Los armadores de Sebastián Caboto: un inglés entre italianos", Anuario de Estudios Americanos, 45 (Sevilla, 1988): 3-65.

Gil, Juan, Los conversos y la Inquisición sevillana, Sevilla, Universidad de Sevilla / Fundación El Monte, 2001, vols. III y IV.

Godinho, Vitorino Magalhães, Os descobrimentos e a economia mundial, Lisboa, Editorial Presença, 1991, 4 vols.

González Arce, José Damián, El negocio fiscal en la Sevilla del siglo XV. El almojarifazgo mayor y las compañias de arrendatarios, Sevilla, Diputación de Sevilla, 2017.

Gual Camarena, Miguel, Vocabulario del comercio medieval, Barcelona, Ediciones El Albir, 1976. 
Guidi Bruscoli, Francesco, Bartolomeo Marchionni «Homem de grossa fazenda» (ca. 1450-1530). Un mercante fiorentino a Lisbona e l'impero portoghese, Florencia, Leo S. Olschki Editore, 2014.

Guiral-Hadziiossif, Jacqueline, Valencia puerto mediterráneo en el siglo XV (1410-1525), Valencia, Edicions Alfons el Magnànim, 1989.

Heers, Jacques, Gênes au XVe siècle, París, SEVPEN, 1961.

Iradiel Murugarren, Paulino, Evolución de la industria textil castellana en los siglos XIII-XVI, Salamanca, Universidad de Salamanca, 1974.

Krueger, Hilmar C., "Genoese Trade with Northwest Africa in the Twelfth Century", Speculum 8 (Chicago, 1933): 377-395.

Ladero Quesada, Miguel Ángel, Las Indias de Castilla en sus primeros años. Cuentas de la Casa de la Contratación (1503-1521), Madrid, Dykinson, 2008.

Lopez, Robert S., "Star and spices: the earliest italian manual of commercial practice", Explorations in Economic History, 7 (San Diego, 1969): 35-42.

López Beltrán, María Teresa, El puerto de Málaga en la transición a los tiempos modernos, Málaga, Universidad de Málaga, 1986.

Lorenzo Sanz, Eufemio, Comercio de España con América en la época de Felipe II, Valladolid, Diputación Provincial de Valladolid, 1979, 2 tomos.

Maneuvrier, Christophe, Daeffler, Michel y Bretthauer, Isabelle, "Les importations de bois de Brésil en Normandie dans la première moitié du XVIe siècle", Revista Portuguesa de História, 49 (Coimbra, 2018): 189-213.

Martín Acosta, Emelina, "La carrera indiana de un prohombre burgalés: García de Lerma”, Boletín de la Institución Fernán González, 73 (Burgos, 1994): 39-52.

Matos, Artur Teodoro de (coord.), “A colonização atlántica”, Joel Serrão y A. H. de Oliveira Marques (dirs.), Nova História da Expansão Portuguesa, Lisboa, Editorial Estampa, 2005, vol. III, tomo 2.

Mauro, Frédéric, Portugal, o Brasil e o Atlântico, Lisboa, Editorial Estampa, 1997, 2 vols.

Medina, José Toribio, El veneciano Sebastián Caboto al servicio de España, Santiago de Chile, Imprenta y Encuadernación Universitaria, 1908, 2 vols.

Mira Caballos, Esteban, La gran armada colonizadora de Nicolás de Ovando, 1501-1502, Santo Domingo, Academia Dominicana de la Historia, 2014.

Mollat, Michel, Le commerce maritime normand a la fin du Moyen Age, París, Librairie Plon, 1952.

Monumenta Missionaria Africana. África Ocidental (1342-1499), coligida e anotada pelo Padre António Brásio, 2. a serie, Lisboa, Agência do Ultramar, 1958, vol. I. 
Morales Padrón, Francisco, "Canarias en el Archivo de Protocolos de Sevilla”, Anuario de Estudios Atlánticos, 7 (Las Palmas de Gran Canaria, 1961): 239-338.

Morales Padrón, Francisco, Teoría y leyes de la conquista, Sevilla, Universidad de Sevilla, 2008.

Mueller, Reinhold C., "La situación económica de Italia en la Baja Edad Media", Ferdinand Seibt y Winfried Eberhard (eds.), Europa 1400. La crisis de la Baja Edad Media, Barcelona, Crítica, 1992: 181-195.

Muro Orejón, Antonio, Pérez-Embid, Florentino y Morales Padrón, Francisco (eds.), Pleitos Colombinos. I. Proceso hasta la sentencia de Sevilla, Sevilla, Escuela de Estudios Hispanoamericanos, 1967.

Otte, Enrique, Cédulas reales relativas a Venezuela (1500-1550), Caracas, Fundación John Boulton, 1963.

Otte, Enrique, Las perlas del Caribe: Nueva Cádiz de Cubagua, Caracas, Fundación John Boulton, 1977.

Otte, Enrique, Sevilla y sus mercaderes a fines de la Edad Media, Sevilla, Universidad de Sevilla / Fundación El Monte, 1996.

Palenzuela Domínguez, Natalia, Los mercaderes burgaleses en Sevilla a fines de la Edad Media, Sevilla, Universidad de Sevilla, 2003.

Parrado del Olmo, Jesús María y Payo Hernanz, René Jesús, “Un sepulcro vinculado a la casa real en el convento de Nuestra Señora de Gracia de Madrigal de las Altas Torres (Ávila). La abadesa María Esperanza de Aragón, hija de Fernando el Católico, y el arquitecto Juan de Vallejo”, Ars \& Renovatio, 4 (Teruel, 2016): 3-21.

Perez, Béatrice, "Francisco de Riberol. Un genovés sevillano canario en el sistema europeo de relaciones", Juan José Iglesias Rodríguez y José Jaime García Bernal (eds.), Andalucía en el mundo atlántico moderno. Agentes y escenarios, Madrid, Sílex, 2016: 195-213.

Pérez de Colosía, María Isabel y Gil Sanjuán, Joaquín, "El tráfico de Málaga con las Indias en tiempos de Carlos I", Revista de Indias, 38 (Madrid, 1978): 563-592.

Pérez García, Rafael M., "El capital burgalés y la conexión de Sevilla con el eje económico del norte de Europa a comienzos del reinado de Carlos I", en Juan José Iglesias Rodríguez y José Jaime García Bernal (eds.), Andalucía en el mundo moderno. Agentes y escenarios, Madrid, Sílex, 2016: 35-57.

Pérez García, Rafael M., "Mercaderes burgaleses en la Andalucía de los siglos XVI y XVII: procesos de enriquecimiento, ascenso social y ennoblecimiento", José Ignacio Fortea Pérez, Juan Eloy Gelabert González, Roberto López Vela y Elena Postigo Castellanos (coords.), Monarquías en conflicto. Linajes y noblezas en la articulación de la monarquía hispánica, Madrid, Fundación Española de Historia Moderna / Universidad de Cantabria, 2018: 617-627. 
Pérez García, Rafael M., “El mercader Diego Díaz y la conexión burgalesa del viaje de Magallanes", Emilio José Luque Azcona y José Miranda Bonilla (eds.), A 500 años de la Primera Vuelta al Mundo. Una mirada histórica a la expedición de Magallanes-Elcano, Sevilla, Editorial Universidad de Sevilla, 2020.

Ramos Pérez, Demetrio, La fundación de Venezuela. Ampiés y Coro: una singularidad histórica, Valladolid, Coro, 1978.

Ramos Pérez, Demetrio, "El grupo financiero de Burgos en el momento que dominó la empresa ultramarina", Primeras Jornadas de Historia. Burgos y América, Burgos, Caja de Ahorros Municipal de Burgos, 1992: 131-157.

Río, Justo L. del, Los inicios de la agricultura europea en el Nuevo Mundo (1492-1542), Sevilla, ASAJA, 1991.

Rumeu de Armas, Antonio, Cádiz, metrópoli del comercio con África en los siglos XV y XVI, Cádiz, Caja de Ahorros de Cádiz, 1976.

Salvador Esteban, Emilia, "Un aspecto del comercio canario de exportación en el siglo XVI: las relaciones con el puerto de Valencia", Espacio, Tiempo y Forma. Serie IV, Historia Moderna, 1 (Madrid, 1988): 623-638.

Sánchez Martín, Margarita, "El tráfico de la orchilla de Berbería, un disputado negocio entre mercaderes burgaleses", II Congreso de Jóvenes Historiadores y Geógrafos, Valencia, 1992: 166-174.

Santana Pérez, Juan Manuel y Santana Pérez, Germán, La pesca en el banco sahariano. Siglos XVII y XVIII, Madrid, Los Libros de la Catarata, 2014.

The overseas trade of Bristol in the later Middle Ages, Bristol, 1937, vol. VII.

The Travels of Marco Polo. The Complete Yule-Cordier Edition, New York, Dover Publications, 1993, vol. II.

Ulloa, Modesto, La Hacienda real de Castilla en el reinado de Felipe II, Madrid, Fundación Universitaria Española, 1977.

Vespucio, Américo, El Nuevo Mundo. Viajes y documentos completos, Madrid, Akal, 1985.

Vogt, John, "Notes on the portuguese cloth trade in West Africa, 1480-1540", The International Journal of African Historical Studies, 8 (Boston, 1975): 623-651.

Wallerstein, Immanuel, El moderno sistema mundial, Madrid, Siglo XXI, 2010, 3 vols.

Fecha de recepción: 9 de enero de 2020.

Fecha de aceptación: 1 de junio de 2020. 


\section{The impact of American brazilwood on European markets: transnational commercial networks and monopolistic politics, $1499-1530$}

The arrival of the Spanish and Portuguese in the Americas led to significant brazilwood trading with Europe, where textile industries began using it during the first three decades of the sixteenth century, displacing Asian timber. This article studies its distribution in major European markets, with a focus on the attempts of different groups of merchants to control this American product. The research is based on abundant primary sources found in the Archivo General de Indias, Archivo General de Simancas and in the notarial records of Seville preserved in the Archivo Histórico Provincial de Sevilla.

KEY WORDS: brazilwood; European textile industry; merchants; European markets. 